\title{
Rural Safety Net Use During the Covid-19 Pandemic
}

[This pre-print is currently under peer review.]

January 18,2021

Kathryn McConnell ${ }^{\mathrm{a}}$, Alexis A. Merdjanoff ${ }^{\mathrm{b}}$, Paul Berne Burow ${ }^{\mathrm{c}}$, J. Tom Mueller ${ }^{\mathrm{d}}$, and Justin Farrell ${ }^{\mathrm{e}}$

a. Yale School of the Environment, Yale University, 195 Prospect Street, New Haven, CT 06511.

b. New York University School of Global Public Health, New York University, New York, NY 10012.

c. Department of Anthropology, Yale University, New Haven, CT 06511.

d. Department of Sociology, Social Work, and Anthropology, Utah State University, Logan, UT 8432.

e. Yale School of the Environment, Yale University, 195 Prospect Street, New Haven, CT 06511. 


\begin{abstract}
Despite unparalleled government relief spending, many households have fallen into financial distress during the Covid-19 pandemic. At the same time, reports of non-governmental forms of disaster aid - both from organizations and among individuals - are widespread. Given that formal government programs have not fully met the material needs of many households across the United States during the pandemic, we build on disaster scholarship to compare utilization of three distinct forms of disaster support to better understand how households are getting by: (1) government safety net programs, (2) not-for-profit support, and (3) informal social support. We focus our study on a large, yet especially vulnerable and under-researched population: rural residents across the Western U.S. Drawing on results from a representative survey fielded during the summer of 2020, we find that informal social support was the most widely used safety net, with over half of all residents giving or receiving some form of informal support. However, differences in age, education, sex, race, ethnicity, and homeownership status variously predicted different types of safety net use, demonstrating the unevenness of pandemic impacts and access to relief resources across demographic groups. Finally, rural residents who experienced the worst pandemic impacts were the most likely to utilize any of the three forms of safety nets examined. Despite identified limitations to government relief, both formal government programs and informal social support systems were utilized by those most affected by the pandemic.
\end{abstract}




\section{Introduction}

In March of 2020, the United States federal government administered more than $\$ 600$ billion in direct payments to households nationwide in an attempt to address the acute and widespread impacts of the Covid-19 pandemic (Bitler, Hoynes, and Schanzenbach 2020a). The Families First Coronavirus Act and the Coronavirus Aid, Relief, and Economic Security (CARES) Act expanded existing government safety net infrastructure, created new programs, and gave funds to states and cities. But despite this historic level of government spending, research shows that many households have remained in financial distress (Saloner et al. 2020) and millions of U.S. residents have been pushed into poverty since the pandemic began (Parolin et al. 2020). These findings suggest that government programs such as the CARES Act have not adequately addressed the financial needs of households impacted by the pandemic, and raises an important and largely unanswered question: What formal and informal resources are households using to close the gap created by insufficient government programs?

While research on social safety nets tends to emphasize formalized government programs, scholars have documented the growing role that not-for-profit organizations now play in meeting material needs where the state or the market are absent (Guo 2010; Salamon 1994). Additionally, disaster scholarship has documented the critical role that informal social support systems play during disaster response and recovery (Aldrich 2012). Empirical research further suggests that these three distinct forms of disaster support - government safety net programs, not-for-profit support, and informal social support - are not equally available or equally utilized across demographic groups and geographies (Aldrich 2012; Howell and Elliott 2018; Wu 2019). While these findings are consistent across well-studied environmental disasters, there is limited understanding regarding how these forms of disaster support are accessed during a pandemic.

Because of their high levels of poverty, health-compromised populations, and vulnerable labor markets, rural regions stand out as especially vulnerable to pandemic impacts, likely resulting in high levels of material need (Cutter, Ash, and Emrich 2016; Matthews et al. 2017; Weber and Miller 2017). While much attention has been given to the relationship between urban density and the pandemic (Hamidi, Sabouri, and Ewing 2020), the geographically dispersed condition of rural living also creates unique vulnerabilities to the pandemic. Rural communities have been found to be highly susceptible to Covid-19 spread and its most serious complications (Ameh et al. 2020; Peters 2020), and generally start with less capacity to recover from disasters (Amaro and Willyard 2020; Cutter et al. 2016).

There is still limited empirical research that describes the impacts of the pandemic or documents the support systems residents are using to survive the ongoing disaster in rural areas. The prevailing research emphasis on national-level and demographic group-specific analyses means that rural communities - which constitute nearly $20 \%$ of the United States' population (U.S. Census Bureau 2017) and live in distinct structural conditions from their non-rural counterparts - are being largely overlooked in critical Covid-19 research efforts. This lack of robust empirical research on the impacts of the pandemic in rural areas means that key response and recovery policies may be developed with limited understanding of rural needs and how these populations access formal recovery mechanisms.

We examine the following key questions: During the pandemic summer of 2020, as the first major wave of Covid-19 cases spread across rural regions, which formal and informal safety nets did rural residents utilize? And, given what we know about differential access to and utilization of support systems during past disasters, were there differences across demographic groups in levels of safety net use? Finally, did those most impacted by the pandemic utilize safety nets more extensively?

To address these gaps in research on rural America, we fielded a representative survey across all rural counties in the western half of the United States in late June and July of 2020. The survey was designed to broadly assess the social and economic impacts of the pandemic across a large swath of rural America. Our study region - the U.S. West - is characterized by a geographically dispersed population intermixed throughout an extensive patchwork of federally-owned lands and some of the lowest rates of connectivity to urban areas in the country (Cutter et al. 2016). Relative to other rural regions in the U.S., rural West communities tend to have less diversified economies, which can render them more vulnerable to macroeconomic shifts (Cutter et al. 2016; Tickamyer and Duncan 1990). Demographically, this region is home to a large number of Native 
American Tribal Nations and growing Latina/o communities (blind self-citation). While distinct from other rural regions by some measures, findings from this rural West-focused study serve as a starting point for much-needed primary data collection on Covid-19 pandemic impacts across rural America more broadly.

In order to better understand the household-level impacts of the pandemic on the social and economic well-being of rural people, we examined the utilization of three types of safety nets: (1) formal government safety net programs, including Medicaid, Social Security, Supplemental Nutrition Assistance Program (SNAP), Section 8 Housing Choice Vouchers, Unemployment Insurance, and CARES Act stimulus payments; (2) assistance from non-profit organizations, including community-based organizations, faith-based organizations, and food banks; and (3) informal social support, including giving and receiving financial assistance from friends or family and having friends or family move into the home. Where data are available, we compare results to national-level rates. Further, due to the persistent social inequalities found within all regions of the United States, we compare differences in support system use across age, sex, ethnicity, race, education level, and homeownership status. Finally, we examine whether self-reported level of pandemic impacts on respondents' overall lives or household finances is associated with participation in government, non-profit, or informal social support system use.

\section{Background}

\subsection{Rural Vulnerability to Systemic Shocks}

While early social science research on the impacts of Covid-19 has emphasized the pandemic's differential impacts across lines of race, socioeconomic status, age, gender, and dis/ability (Couch, Fairlie, and Xu 2020; Gausman and Langer 2020; Raifman and Raifman 2020; Sabatello, Landes, and McDonald 2020; Wiemers et al. 2020), little research has examined how geographic differences may influence the pandemic's impacts and long-term recovery patterns.

Most research on the pandemic to date relies on national-, state-, or city-level data, often broken down by demographic groups. But certain characteristics of rural regions suggest that they may have unique vulnerabilities as well as specific disaster response and recovery needs. Rural places tend to have lower levels of infrastructure (e.g. internet connectivity and transportation access), less institutional capacity (both governmental and community-based), and less diversified economies (Cutter et al. 2016, blind self-citation). In turn, rural populations have high and persistent levels of poverty (Weber and Miller 2017) and working poverty (Thiede, Lichter, and Slack 2018), and were slower to recover from the economic impacts of the 2008 recession than urban areas (Bennett, Yuen, and Blanco-Silva 2018; United States Department of Agriculture 2017).

Across a number of metrics, healthcare capacity is also much more limited in rural regions. In the past ten years, more than 125 rural hospitals have closed, worsening to the already limited availability of physicians' offices, ICU beds, and ventilators (Henning-Smith, Tuttle, and Kozhimannil 2020; Peters 2020). As a result of these conditions, rural residents are broadly considered a "health disparity population" (Matthews et al. 2017), and tend to experience higher all-cause mortality rates (blind self-citation). Rural populations also tend to have large numbers of senior and elderly residents, concentrated care facilities, and individuals living with a disability, making them especially vulnerable to the pandemic's impacts (Peters 2020).

Further, the pandemic will likely exacerbate pre-existing health and healthcare disparities within rural regions. For instance, prior to the pandemic, rural counties with large shares of Black or Native American residents had higher premature death rates than predominantly white counties (C. E. Henning-Smith et al. 2019) and rural Latina/o residents had lower levels of access to preventative care services than non-Latina/o rural residents (C. Henning-Smith et al. 2019). Already, higher death rates have been documented during the pandemic in rural counties with large shares of Latina/o or Black residents (Cheng, Sun, and Monnat 2020). 


\subsection{Available Support Systems}

Providing the full scope of needed assistance - including healthcare and social services as well as educational, childcare, and economic support - across such a geographically dispersed population is a core challenge for rural recovery from the Covid-19 pandemic. But even without considering the unique challenges posed in rural regions, research and reporting have illustrated that existing government safety nets are limited in their capacity to respond quickly and effectively to the pandemic for a number of reasons.

Since the 1990s, the government social safety net in the United States has undergone substantial changes, leaving out poor households that fail to meet employment tests for access to formal government programs (Danziger 2010; Tach and Edin 2017). Even if changes in funding for the overall suite of government welfare programs represents an expansion of the safety net in gross monetary terms, the persistence of poverty shows that it remains insufficient to address the needs of the most vulnerable in society (Edin and Shaefer 2015).

The increased tethering of safety net eligibility to work requirements in particular (Loprest and Nightingale 2018) has made such programs especially fraught during the pandemic's time of intermittent lockdowns and widespread job losses (Bitler, Hoynes, and Schanzenbach 2020b). Following the 2008 recession during a comparable period of heightened unemployment, this structural characteristic of government safety net programs resulted in increasing poverty levels among low-income earners (Bitler and Hoynes 2015). Further, programs' eligibility requirements exclude certain populations. For instance, undocumented immigrants are ineligible for a number of safety net programs (Clark et al. 2020), which is especially concerning for the many rural communities which include undocumented residents (Nelson, Trautman, and Nelson 2015). Additionally, even for those who were eligible for government safety nets, program infrastructure was often overwhelmed by the sudden influx of applicants, causing delays or inability to access benefits (Bitler et al. 2020a). Finally, even among individuals who were both eligible and able to successfully navigate government application procedures, the amount of resources available in many cases has not been sufficient to meet material needs (Bitler et al. 2020a). And in a more recent trend, states which mistakenly overpaid benefits are now trying to recoup them from recipients who already spent the funds and may still need financial support (Weber 2020).

Since the 1980's, the provision of social services has increasingly devolved from government purview to the private or non-profit sector (Marwell 2004; Salamon 1994). Subsequently, researchers have critiqued an overemphasis on formal government programs in research on material well-being (Guo 2010). For this reason, we examine both reported government program use as well as reliance on non-profit resources during the pandemic. However, there is a documented scarcity of non-profits in rural regions (Wu 2019), which instead tend to concentrate in urban areas (Hammack and Smith 2018). In the rural Western United States in particular, there are fewer religious and civic organizations than in other rural regions (Cutter et al. 2016).

During the pandemic, what are now popularly described as "mutual aid" practices have been documented around the world (Matthewman and Huppatz 2020). But researchers have yet to analyze these informal practices, including questions around who participates, in what context, and how. Disaster scholars have made the strong case that such informal social supports are a critical component of post-disaster recovery. For instance, scholars have documented the rise in helping behaviors (Webb 2018) and the creation of new social networks (Messias, Barrington, and Lacy 2012) during and in the aftermath of disasters. In some instances, the presence of such support systems are found to increase the speed of recovery (Sadri et al. 2018). Some scholars have even argued that social capital, more so than any other factor including government assistance, "serves as the core engine of [disaster] recovery" (Aldrich 2012:15).

Sharing a household with relatives or nonkin is a widely-documented social practice and source of informal social support to weather financial hardship. Scholars have described the heightened prevalence of this practice, also known as "doubling up", among families with young children, renters, Latina/o's, single mothers, individuals with low educational attainment or income levels (Pilkauskas, Garfinkel, and McLanahan 2014), and individuals who have recently lost employment (Wiemers 2014). Doubling up is also used as a disaster-response strategy (Aldrich 2012:46; Reid 2013) and the practice increased in prevalence nationwide following the 2008 financial recession (Mykyta and Macartney 2012). Recent work has documented a rise in doubling up in Massachusetts during the Covid-19 pandemic in response to increasing housing costs (Arcaya et al. 2020). Notably, the financial benefits associated with doubling up (via rental or mortgage savings) 
are significant, in many cases comparable to the financial value of formal government safety net programs (Pilkauskas et al. 2014). However, despite financial savings, scholars have documented that doubling up can have long-term adverse health impacts on children living in the household (Harvey 2020), so it should not be considered a uniformly beneficial response to financial distress.

\section{Methods}

\subsection{Data}

We conducted a representative survey of all rural counties across eleven Western states: Arizona, California, Colorado, Idaho, Montana, Nevada, New Mexico, Oregon, Utah, Washington, and Wyoming. For this study, counties are defined as rural if they are categorized as non-metropolitan by the United States Office of Management and Budget. Two hundred and seventy eight total counties were included in our sampling frame, and the results are representative of the population with a sampling error of $\pm 3.1 \%$ at the $95 \%$ confidence level. Full question texts are included in the Appendix section 3. The survey was fielded by a professional survey firm between June 25th and July 22nd of 2020, and collected a total of 1,009 responses. Households were selected randomly from the U.S. Postal Delivery Sequence File and matched with contact information from public databases. Selected households were contacted by phone, email, and postcard, and interviews were available in both English and Spanish. We utilized soft quotas and over-sampling in an attempt to collect representative responses from Native Americans, Latina/o's, and young adults - groups which are historically harder to reach in rural surveys. The survey's contact rate was $3.0 \%$ and its complete interview response rate was 1.1\%, calculated using standard AAPOR rates (American Association for Public Opinion Research 2016). While lower than ideal, this is representative of larger trends in survey research, which have seen major declines in response rates in recent years (Stedman et al. 2019). The survey was conducted with approval from Yale University's University's Human Research Protection Program (exemption determination ID\#2000027941).

\subsection{Analysis}

We conducted all analyses with $\mathrm{R}$ statistical software version 3.6.3. We implemented rake weights for difficult-to-reach populations, including Latina/o identity, Native American identity, age, sex, education level, and state. Descriptive point estimates are reported with a $95 \%$ confidence interval and relationships between demographic variables, pandemic impacts, and safety net use are evaluated with linear probability models at the $\mathrm{p}<.05$ level. We report the results of bivariate models, and note any instances in which multivariable models yield different results. Fully adjusted models include age, sex, ethnicity, race, education, and homeownership status.

The weighted sample was generally representative of the target population. Our independent variables are categorized as follows: Age is grouped into 18-34, 35-49, 50-64, and 65+ years. Sex includes only self-identified female or male respondents. Ethnicity captures whether a respondent identifies as Latina or Latino. We examine differences in race for self-identified Native American, mixed race, White, or "Other" categories, and exclude remaining categories with two or fewer responses. Education is grouped into less than high school, received a high school diploma or GED, some college, received a Bachelors or Associates, or received a graduate or professional degree. Homeownership status indicates whether a respondent rents or owns their primary dwelling. In addition to demographic characteristics, we asked respondents how the coronavirus pandemic had impacted their overall life and household finances, where 1 is extremely negative, 10 is extremely positive, and 5 is no impact. We bin responses into negative (1-4), no impact (5), and positive impact (6-10). 
Table 1: Demographics of Analytic Sample

\begin{tabular}{|c|c|c|c|c|}
\hline Variable & Total Responses & Unweighted Sample \% & Weighted Sample \% & Nonmetro West Population \% \\
\hline \multicolumn{5}{|l|}{ Age } \\
\hline $18-34$ & 84 & 8.3 & 21.4 & 19.4 \\
\hline $35-49$ & 200 & 19.8 & 28.6 & 16.5 \\
\hline $50-64$ & 281 & 27.8 & 28.6 & 21.7 \\
\hline $65+$ & 409 & 40.5 & 20.4 & 20.1 \\
\hline \multicolumn{5}{|l|}{ Sex } \\
\hline Female & 507 & 50.2 & 48.0 & 49.2 \\
\hline Male & 481 & 47.7 & 50.0 & 50.8 \\
\hline \multicolumn{5}{|l|}{ Ethnicity } \\
\hline Latina/o & 71 & 7.0 & 14.7 & 18.1 \\
\hline Not Latina/o & 895 & 88.7 & 81.1 & 82.0 \\
\hline \multicolumn{5}{|l|}{ Race } \\
\hline White & 837 & 83.0 & 78.0 & 84.6 \\
\hline Native American & 23 & 2.3 & 4.0 & 6.2 \\
\hline Mixed Race & 37 & 3.7 & 5.3 & 3.1 \\
\hline Other & 48 & 4.8 & 6.7 & 3.8 \\
\hline \multicolumn{5}{|l|}{ Education } \\
\hline Less than high school & 17 & 1.7 & 2.5 & 11.7 \\
\hline High school or GED & 159 & 15.8 & 24.2 & 28.7 \\
\hline Some college & 251 & 24.9 & 38.5 & 26.2 \\
\hline Bachelors or Associates & 331 & 32.8 & 21.5 & 24.9 \\
\hline Graduate or Professional Degree & 239 & 23.7 & 12.9 & 8.5 \\
\hline \multicolumn{5}{|l|}{ Housing } \\
\hline Own & 821 & 81.4 & 75.2 & 70.5 \\
\hline Rent & 121 & 12.0 & 17.7 & 29.5 \\
\hline \multicolumn{5}{|l|}{ State } \\
\hline Arizona & 34 & 3.4 & 5.0 & 5.6 \\
\hline California & 138 & 13.7 & 13.8 & 13.4 \\
\hline Colorado & 113 & 11.2 & 12.0 & 11.3 \\
\hline Idaho & 93 & 9.2 & 9.2 & 9.0 \\
\hline Montana & 134 & 13.3 & 11.0 & 10.9 \\
\hline New Mexico & 105 & 10.4 & 11.0 & 4.4 \\
\hline Nevada & 33 & 3.3 & 3.8 & 11.2 \\
\hline Oregon & 128 & 12.7 & 11.1 & 10.7 \\
\hline Utah & 55 & 5.5 & 5.0 & 5.2 \\
\hline Washington & 116 & 11.5 & 12.0 & 11.8 \\
\hline Wyoming & 60 & 5.9 & 6.0 & 6.5 \\
\hline
\end{tabular}

${ }^{\mathrm{a}}$ Population estimates taken from IPUMS National Historical Geographic Information System, ACS five-year estimates, 2014-2018. 


\section{Results}

\subsection{Formal Government Safety Net}

4.1.1. Medicaid Medicaid provides free or low-cost health benefits to children and adults, with special provisions for pregnant women, seniors, and people with disabilities. Recent research conducted across 25 states concluded that there has been an overall increase in Medicaid coverage since the Covid-19 pandemic began, which is largely the result of non-elderly adults seeking to replace employer-sponsored coverage lost as the result of unemployment (Frenier, Nikpay, and Golberstein 2020). We find that 10.7\%, CI [ 7.9\%, 13.5\%] of rural West households reported that they received Medicaid assistance within the last month (which corresponds to a time period of June to July of 2020). Although not completely comparable because our measure is in reference to the household and federal reporting is at the individual level, this rural level of enrollment is more than ten percentage points lower than national Medicaid enrolled rates during July of 2020 (Center for Medicare \& Medicaid Services 2020).

Since the pandemic began, $2.4 \%$, CI [ $0.8 \%, 3.9 \%$ ] reported that they had gained health insurance coverage, while $4.6 \%$, CI $[2.5 \%, 6.6 \%]$ reported that they had lost health insurance coverage without replacement. Another $6.5 \%$, CI $[4.3 \%, 8.7 \%]$ lacked health insurance both in 2019 before and during the pandemic, while the large majority, $86.6 \%$, CI [83.4\%, 89.8\%] retained coverage during both periods. While we do not have reliable pre-pandemic Medicaid use data, these general health insurance coverage findings and the gap between national- and rural West Medicaid use suggests that national-level upticks in Medicaid enrollment were not equally reflected among rural Westerners during the summer of 2020.

4.1.2. Social Security Social Security provides eligible people with a source of income when they retire. $19.0 \%$, CI $[16.2 \%, 21.8 \%]$ of rural Westerners reported that they or someone in their household received Social Security within the past month, marking it as the most widely utilized permanent government safety net program in our survey. Although facing a similar incongruity between household and individual as the Medicaid comparison, this is on par with the U.S. Census Bureau and Social Security Administration's estimate that $18.7 \%$ of individuals nationwide received Social Security benefits in July 2020 (Social Security Administration Research, Statistics, and Policy Analysis 2020).

4.1.3. Supplemental Nutrition Assistance Program (SNAP) Supplemental Nutrition Assistance Program (SNAP) provides eligible people with benefits cards, used like debit cards, to buy food at authorized grocery stores and farmers markets. At the national level, research has documented that participation in SNAP had increased by $17 \%$ in May of 2020 relative to February of the same year, and that total government spending on SNAP programs had increased over $200 \%$ by July of 2020 (Bitler et al. 2020a). During the summer of $2020,6.7 \%$, CI [4.2\%,9.3\%] of rural West residents reported that they or someone in their household had received SNAP benefits. This is much lower than the national-level estimates of household use, which were reported at 17.29\% as of April of 2020 (U.S. Department of Agriculture Food and Nutrition Service 2020).

4.1.4. Section 8 Housing Vouchers Section 8 Housing Vouchers help low-income families, seniors, and people with disabilities access private rental housing. Rural Westerners utilized Section 8 Housing Choice Vouchers the least frequently of any government safety net program, with $1.8 \%$, CI [0.7\%, 2.8\%] reported that someone in their household had received a voucher during the past month.

4.1.5. Unemployment Insurance Each U.S. state runs its own Unemployment Insurance program that pays eligible people money if they lose their job through no fault of their own. 12.3\%, CI [9.4\%, 15.2\%] of rural Westerners reported utilizing unemployment benefits within their household during the summer of 2020, mirroring national trends from the same time period (Federal Reserve Bank of St. Louis 2020a). 
4.1.6. General Government Safety Net Use Established safety net programs such as those described above are a key means of support for households experiencing financial hardship. We find that $36.2 \%$, CI $[32.2 \%, 40.1 \%]$ of households used at least one of the permanent government safety net programs described above. Key differences emerged across demographic groups for general government program use, with those 65 years or older and women reporting higher levels of use. In contrast, those with a high school degree or higher tended to use government programs at lower rates than those with no high school degree. These findings are durable across both bivariate and multivariable models. Those who reported their race as "Other" also reported significantly lower levels of government program use, though this variable was only significant in the bivariate model.

4.1.7. CARES Act Stimulus Payments The Internal Revenue Service issued payments to eligible people under the CARES Act in the amount of $\$ 1,200$, or $\$ 2,400$ if married filing jointly, plus $\$ 500$ for each qualifying child. $67.6 \%$, CI [63.8, 71.5\%] of rural Westerners received stimulus assistance from the CARES Act by the summer of 2020 , compared to an estimated $81.2 \%$ of the national population (Coibion, Gorodnichenko, and Weber 2020).

4.2. Nongovernmental Safety Net Research conducted at the national level has emphasized spikes in food pantry use during the pandemic (Saloner et al. 2020). Between 2002 and 2018, Bitler, Hoynes, and Schanzenbach $2020 \mathrm{~b}$ document that, at most slightly more than $3.5 \%$ of households nationwide received food from a food pantry within the last month during this 16-year pre-pandemic time period (23). We find that $6.0 \%$, CI $[3.8 \%, 8.2 \%]$ of rural Westerners received resources from a food pantry within the previous month during the summer of 2020 , nearly twice as high as pre-pandemic national peaks.

Rural Westerners reported relatively low levels of receiving assistance from community-based organizations or faith-based organizations; only $3.2 \%$, CI $[1.6 \%, 4.8 \%]$ reported doing so within the past month.

Taken together, $7.6 \%$, CI $[5.2 \%, 10.0 \%]$ of rural Westerners relied on community-based organization, faithbased organization, or food pantry resources during the summer of 2020. These resources were not accessed similarly across racial groups, with both Native Americans and those who identified as mixed race reporting significantly lower levels - nearly no use - of any non-profit support compared to white respondents.

\subsection{Informal Social Safety Net}

4.3.1. Receiving or Giving Financial Assistance to Friends or Family Members Survey respondents reported receiving financial assistance from friends or family at slightly higher levels than they did from non-profit organizations, with 9.4\%, CI [6.7\%, 12.2\%] reported receiving assistance within the last month. During the pandemic, the older the age group, the lower the level of receiving financial assistance from friends or family, with those 65 years or older being the least likely to receive any assistance, $2.8 \%$, CI [0.9\%, $4.7 \%]$ compared to $20.1 \%$, CI [10.4\%, 29.7\%] of 18-34 year olds. Likewise, those who reported their race as "Other" received informal assistance at significantly lower levels than other racial groups. Compared to homeowners, a significantly higher percentage of renters received financial assistance from friends or family during the pandemic, at $17.7 \%$, CI $[8.9 \%, 26.6 \%]$ compared to $7.8 \%$, CI $[4.9 \%, 10.8 \%]$ of homeowners. Renter status becomes non-significant in the fully adjusted model, which is partially the result of fewer available complete observations but further mediated by the inclusion of age or education status variables.

In contrast to receiving assistance, respondents reported much higher levels of giving financial assistance to a friend or family member, with $38.0 \%$, CI $[33.9 \%, 42.1 \%]$ reporting they had done so since the pandemic began. This is nearly the same percentage of the population that received any form of government assistance (excluding stimulus payments), suggesting that this form of informal social support is at least as widespread as use of government programs. There were no significant differences in giving across demographic groups, with the exception of Latina/o's, $53.2 \%$, CI $[38.4 \%, 68.0 \%]$ of who reported giving financial assistance to friends or family during the pandemic, compared to only $35.6 \%$, CI [31.5\%, 39.7\%] of non-Latina/o's. 
4.3.2. Doubling Up The large majority of survey respondents reported that during the summer of 2020 their housing situation was secure, with $93.2 \%$, CI [90.5\%, 95.9\%] reporting that their housing had remained secure both before and during the pandemic, and another $1.7 \% \mathrm{CI}[0.2 \%, 3.1 \%]$ having gained housing security since the pandemic began. Only 3.5\% CI $[1.6,5.4]$ reported becoming housing insecure by the time of the survey, with another $1.6 \% \mathrm{CI}[0.2 \%, 3.0 \%]$ remaining housing insecure from prior to the pandemic. This proportion of reported housing insecurity reads as slightly lower than related national-level estimates from spring of 2020, which found that $9 \%$ of households had no confidence in their ability to make the next rent or mortgage payment (Bitler et al. 2020a:34).

Direct impacts to housing security - for example through a job loss and subsequent difficulty paying mortgage or rent - are not the only means by which the pandemic has influenced housing situations. Media outlets have reported increasing numbers of younger adults moving in with parents (Hsu 2020), and, to a lesser extent, grandparents moving in with adult children to assist with grandchildren's childcare (Blum 2020). A national-level study conducted by the Pew Research Center found that, by the time our survey was fielded, nearly one fifth of all adults living in the U.S. had themselves moved or knew someone else who had. Among those who relocated, around $60 \%$ moved in with a family member (Cohn 2020).

Our results suggest that in rural West regions during the summer of 2020, these indirect impacts of the pandemic on housing - having a friend or family member move into the home - were widespread. 19.3\%, CI $[15.9 \%, 22.7 \%]$ of rural Westerners had another person move into their home, also known as "doubling up", since the pandemic began. Of those who reported that this was the case, the median number of people who moved in was 1, but the mean was 1.4, CI $[1.3,1.6]$, indicating that a number of households took in more than one additional member during the pandemic. Notably, these estimates likely represent an underestimate of the total percentage of rural Westerners who doubled up since the pandemic began, as we only ask respondents whether they had hosted friends or family in their household, and not whether they themselves had moved into a different household.

In contrast to anecdotal descriptions of adult children moving in with their parents, our results do not find any significant differences across age groups. However, $42.5 \%$, CI [19.8\%, 65.1\%] of mixed race respondents reported doubling up, a significantly higher percentage than any other racial group, although this difference is not significant in the multivariable model.

Females reported significantly higher levels of doubling up, with $23.6 \%$, CI [18.5\%, 28.9\%] reporting they had a friend or family member move in, compared to only $15.3 \%$, CI $[10.8 \%, 19.8 \%]$ of men. To try to understand whether this difference might be evidence of friends or family members moving in to assist with childcare, we further evaluate whether the presence of any children under the age of 16 is associated with higher levels of doubling up. While presence of a child in the home is a significant predictor of doubling up in the bivariate model, the variable becomes insignificant in the fully adjusted model while sex remains significant. While these results cannot definitively conclude the reasons why friends or family may have moved into a household, they provide some evidence for the idea that people moved to assist with childcare, and do not support the narrative that adult children were moving back to their parents' homes during this period. 
Table 2: Multivariable Linear Probability Model: Safety Net Participation

\begin{tabular}{|c|c|c|c|c|c|}
\hline & \multicolumn{5}{|c|}{ Dependent variable: } \\
\hline & $\begin{array}{l}\text { Government Assistance } \\
(1) \\
\end{array}$ & $\begin{array}{l}\text { Non-profit Assistance } \\
\qquad(2) \\
\end{array}$ & $\begin{array}{l}\text { Received Informal Support } \\
\qquad(3) \\
\end{array}$ & $\begin{array}{l}\text { Gave Informal Support } \\
(4) \\
\end{array}$ & $\begin{array}{c}\text { Doubled Up } \\
(5) \\
\end{array}$ \\
\hline Constant & $\begin{array}{c}0.473^{* * *} \\
(0.189,0.756)\end{array}$ & $\begin{array}{c}0.291^{* *} \\
(0.014,0.568)\end{array}$ & $\begin{array}{c}0.359^{* *} \\
(0.078,0.640)\end{array}$ & $\begin{array}{c}0.379^{* *} \\
(0.047,0.710)\end{array}$ & $\begin{array}{c}0.122 \\
(-0.212,0.456)\end{array}$ \\
\hline Age: $35-49$ & $\begin{array}{c}0.056 \\
(-0.083,0.195)\end{array}$ & $\begin{array}{c}0.012 \\
(-0.082,0.106)\end{array}$ & $\begin{array}{c}-0.118^{* *} \\
(-0.233,-0.003)\end{array}$ & $\begin{array}{c}0.040 \\
(-0.112,0.192)\end{array}$ & $\begin{array}{c}-0.017 \\
(-0.154,0.120)\end{array}$ \\
\hline Age: 50-64 & $\begin{array}{c}0.050 \\
(-0.078,0.179)\end{array}$ & $\begin{array}{c}-0.041 \\
(-0.125,0.044)\end{array}$ & $\begin{array}{c}-0.135^{* *} \\
(-0.248,-0.023)\end{array}$ & $\begin{array}{c}0.037 \\
(-0.105,0.178)\end{array}$ & $\begin{array}{c}0.023 \\
(-0.110,0.156)\end{array}$ \\
\hline Age: $65+$ & $\begin{array}{c}0.336^{* * *} \\
(0.210,0.463)\end{array}$ & $\begin{array}{c}-0.048 \\
(-0.132,0.036)\end{array}$ & $\begin{array}{c}-0.182^{* * *} \\
(-0.292,-0.073)\end{array}$ & $\begin{array}{c}-0.061 \\
(-0.197,0.076)\end{array}$ & $\begin{array}{c}-0.049 \\
(-0.178,0.080)\end{array}$ \\
\hline Female & $\begin{array}{c}0.074^{*} \\
(-0.004,0.152)\end{array}$ & $\begin{array}{c}0.029 \\
(-0.019,0.077)\end{array}$ & $\begin{array}{c}-0.018 \\
(-0.077,0.040)\end{array}$ & $\begin{array}{c}0.019 \\
(-0.067,0.105)\end{array}$ & $\begin{array}{c}0.079^{* *} \\
(0.007,0.150)\end{array}$ \\
\hline Latina or Latino & $\begin{array}{c}-0.028 \\
(-0.171,0.115)\end{array}$ & $\begin{array}{c}0.011 \\
(-0.079,0.101)\end{array}$ & $\begin{array}{c}0.027 \\
(-0.084,0.139)\end{array}$ & $\begin{array}{c}0.179^{* *} \\
(0.010,0.348)\end{array}$ & $\begin{array}{c}0.109 \\
(-0.045,0.262)\end{array}$ \\
\hline Native American & $\begin{array}{c}-0.101 \\
(-0.314,0.112)\end{array}$ & $\begin{array}{c}-0.080^{* *} \\
(-0.146,-0.013)\end{array}$ & $\begin{array}{c}0.004 \\
(-0.207,0.215)\end{array}$ & $\begin{array}{c}0.240^{*} \\
(-0.039,0.518)\end{array}$ & $\begin{array}{c}-0.025 \\
(-0.245,0.195)\end{array}$ \\
\hline Mixed Race & $\begin{array}{c}0.063 \\
(-0.156,0.281)\end{array}$ & $\begin{array}{c}-0.100^{* * *} \\
(-0.164,-0.036)\end{array}$ & $\begin{array}{c}-0.017 \\
(-0.174,0.140)\end{array}$ & $\begin{array}{c}0.052 \\
(-0.165,0.268)\end{array}$ & $\begin{array}{c}0.205^{*} \\
(-0.026,0.435)\end{array}$ \\
\hline Other Race & $\begin{array}{c}-0.093 \\
(-0.240,0.054)\end{array}$ & $\begin{array}{c}0.025 \\
(-0.081,0.132)\end{array}$ & $\begin{array}{c}-0.102^{* *} \\
(-0.186,-0.017)\end{array}$ & $\begin{array}{c}0.091 \\
(-0.117,0.298)\end{array}$ & $\begin{array}{c}0.033 \\
(-0.169,0.235)\end{array}$ \\
\hline High School Graduate & $\begin{array}{c}-0.261^{*} \\
(-0.534,0.011)\end{array}$ & $\begin{array}{c}-0.236^{*} \\
(-0.498,0.026)\end{array}$ & $\begin{array}{c}-0.136 \\
(-0.394,0.122)\end{array}$ & $\begin{array}{c}-0.172 \\
(-0.486,0.143)\end{array}$ & $\begin{array}{c}-0.021 \\
(-0.324,0.282)\end{array}$ \\
\hline Some College, No Degree & $\begin{array}{c}-0.198 \\
(-0.470,0.075)\end{array}$ & $\begin{array}{c}-0.208 \\
(-0.470,0.055)\end{array}$ & $\begin{array}{c}-0.148 \\
(-0.405,0.108)\end{array}$ & $\begin{array}{c}-0.055 \\
(-0.364,0.253)\end{array}$ & $\begin{array}{c}0.029 \\
(-0.267,0.326)\end{array}$ \\
\hline College Degree & $\begin{array}{c}-0.324^{* *} \\
(-0.590,-0.058)\end{array}$ & $\begin{array}{c}-0.232^{*} \\
(-0.493,0.029)\end{array}$ & $\begin{array}{c}-0.173 \\
(-0.426,0.080)\end{array}$ & $\begin{array}{c}-0.014 \\
(-0.321,0.292)\end{array}$ & $\begin{array}{c}-0.043 \\
(-0.336,0.251)\end{array}$ \\
\hline Graduate Degree & $\begin{array}{c}-0.265^{*} \\
(-0.537,0.007)\end{array}$ & $\begin{array}{c}-0.226^{*} \\
(-0.485,0.033)\end{array}$ & $\begin{array}{c}-0.150 \\
(-0.405,0.105)\end{array}$ & $\begin{array}{c}0.021 \\
(-0.287,0.329)\end{array}$ & $\begin{array}{c}0.016 \\
(-0.277,0.309)\end{array}$ \\
\hline Renter & $\begin{array}{c}0.045 \\
(-0.058,0.148)\end{array}$ & $\begin{array}{c}0.050 \\
(-0.026,0.126)\end{array}$ & $\begin{array}{c}0.028 \\
(-0.057,0.113)\end{array}$ & $\begin{array}{c}-0.031 \\
(-0.164,0.102)\end{array}$ & $\begin{array}{c}0.018 \\
(-0.090,0.127)\end{array}$ \\
\hline Child in Household & & & & & $\begin{array}{c}0.064 \\
(-0.030,0.158) \\
\end{array}$ \\
\hline Observations & 907 & 907 & 907 & 844 & 832 \\
\hline
\end{tabular}

Use of only complete cases causes total observations to vary across models. 


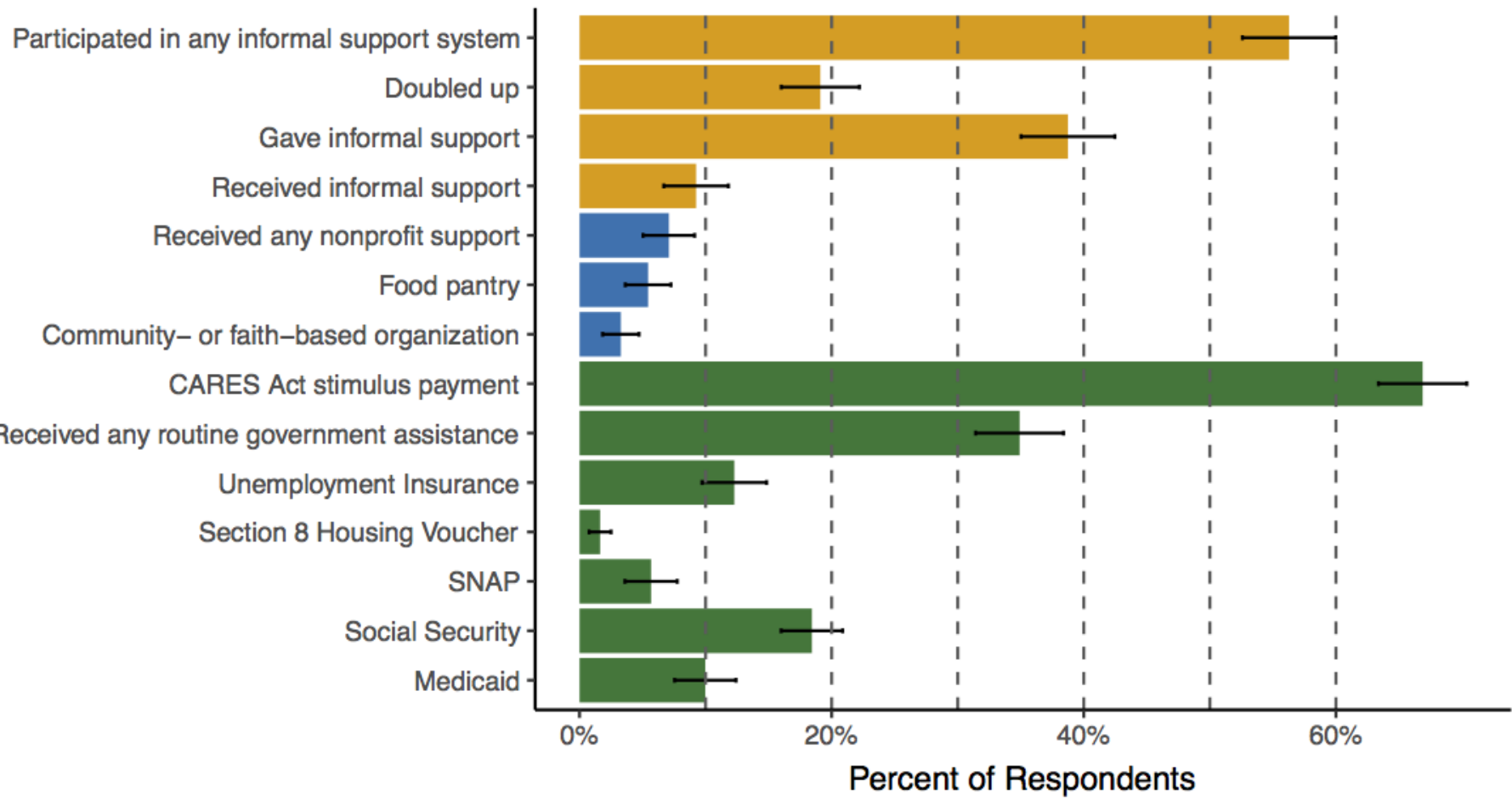




\subsection{Support System Participation and Covid-19 Pandemic Impacts}

Finally, we test whether Covid-19 pandemic impacts are associated with mid-pandemic participation in government safety net programs, nongovernmental safety net support, or informal social safety net giving and receiving.

There were no significant differences among those who experienced varying levels of pandemic impacts on their overall life and their use of any established government assistance programs. In contrast, a significantly higher percentage of those who experienced negative impacts on household finances received assistance from one or more government programs, at $41.5 \%$, CI [34.3\%, 48.7\%] compared to $32.5 \%$, CI [27.3\%, 37.6\%] who reported no financial impacts from the pandemic. Similarly, those who reported negative financial impacts had higher levels of receiving non-profit assistance. This suggests that, although there was generally less government program and non-profit use than participation in informal social support, those who experienced the worst financial repercussions from pandemic were also more likely to rely on various safety nets.

While there were no differences in the percentage of respondents receiving financial assistance from family or friends across the levels of pandemic impact on overall life, those who reported experiencing negative financial impacts from the pandemic received assistance at a significantly higher rate, $16.6 \%$, CI $[10.8 \%$, $22.4 \%]$, compared to those who reported positive, $7.7 \%$, CI $[1.2 \%, 14.1 \%]$, or no financial impacts, $4.7 \%$, CI $[1.7 \%, 7.7 \%]$.

Those who reported negative or positive overall impacts of the pandemic on their lives gave financial assistance to friends or family at significantly higher levels, $43.4 \%$, CI $[37.5 \%, 49.4 \%]$ and $40.7 \%$, CI [31.7\%, 49.7\%] accordingly, compared to those who reported no impact, only $26.7 \%$, CI [20.0\%, 33.4\%] of who supported friends or family financially. Additionally, those who experienced negative financial impacts from the pandemic had significantly higher levels of giving, $43.9 \%$, CI [36.5\%, $51.3 \%]$, compared to $33.1 \%$, CI $[27.5 \%, 38.7 \%]$ of those who reported no financial impacts from the pandemic. 
Table 3: Linear Probability Model: Covid-19 Impacts, Government Assistance, and Non-profit Assistance

\begin{tabular}{lcccc}
\hline \hline & \multicolumn{4}{c}{ Dependent variable: } \\
\cline { 2 - 5 } & Received regular government assistance & \multicolumn{2}{c}{ Received non-profit assistance } \\
& $(1)$ & $(2)$ & $(3)$ & $(4)$ \\
\hline Constant (No Impact) & $0.322^{* * *}$ & $0.325^{* * *}$ & $0.066^{* * *}$ & $0.041^{* * *}$ \\
& $(0.253,0.390)$ & $(0.273,0.376)$ & $(0.023,0.109)$ & $(0.019,0.062)$ \\
Negative Impact on Overall Life & 0.055 & 0.008 & \\
& $(-0.034,0.144)$ & $(-0.046,0.063)$ & \\
Positive Impact on Overall Life & 0.051 & & 0.026 & \\
Negative Impact on Finances & $(-0.057,0.160)$ & $0.090^{* *}$ & $(-0.045,0.098)$ & $0.078^{* * *}$ \\
Positive Impact on Finances & \multicolumn{5}{c}{$0.0 .131)$} \\
& \multicolumn{5}{c}{0.027} & $(-0.036,0.116)$ \\
\hline Observations & 1,009 & $(-0.079,0.133)$ & 1,009 \\
\hline \hline Note: & \multicolumn{5}{c}{1,009} & 1,009 \\
\hline
\end{tabular}


Table 4: Linear Probability Model: Covid-19 Impacts and Informal Social Support

\begin{tabular}{|c|c|c|c|c|c|c|}
\hline & \multicolumn{6}{|c|}{ Dependent variable: } \\
\hline & \multicolumn{2}{|c|}{ Received financial assistance } & \multicolumn{2}{|c|}{ Gave financial assistance } & \multicolumn{2}{|c|}{ Doubled up } \\
\hline & $(1)$ & $(2)$ & $(3)$ & $(4)$ & $(5)$ & $(6)$ \\
\hline Constant (No Impact) & $\begin{array}{c}0.069^{* *} \\
(0.014,0.124)\end{array}$ & $\begin{array}{c}0.047^{* * *} \\
(0.017,0.077)\end{array}$ & $\begin{array}{c}0.267^{* * *} \\
(0.200,0.334)\end{array}$ & $\begin{array}{c}0.331^{* * *} \\
(0.275,0.387)\end{array}$ & $\begin{array}{c}0.398^{* * *} \\
(0.222,0.573)\end{array}$ & $\begin{array}{c}0.261^{* * *} \\
(0.190,0.333)\end{array}$ \\
\hline Negative Impact on Overall Life & $\begin{array}{c}0.046 \\
(-0.021,0.114)\end{array}$ & & $\begin{array}{c}0.167^{* * *} \\
(0.078,0.257)\end{array}$ & & $\begin{array}{c}-0.138 \\
(-0.331,0.054)\end{array}$ & \\
\hline Positive Impact on Overall Life & $\begin{array}{c}0.004 \\
(-0.070,0.078)\end{array}$ & & $\begin{array}{c}0.140^{* *} \\
(0.027,0.252)\end{array}$ & & $\begin{array}{c}-0.179^{*} \\
(-0.375,0.016)\end{array}$ & \\
\hline Negative Impact on Finances & & $\begin{array}{c}0.119^{* * *} \\
(0.054,0.184)\end{array}$ & & $\begin{array}{c}0.108^{* *} \\
(0.015,0.201)\end{array}$ & & $\begin{array}{c}0.082 \\
(-0.073,0.238)\end{array}$ \\
\hline Positive Impact on Finances & & $\begin{array}{c}0.030 \\
(-0.041,0.101) \\
\end{array}$ & & $\begin{array}{c}0.087 \\
(-0.028,0.201)\end{array}$ & & $\begin{array}{c}-0.021 \\
(-0.185,0.142)\end{array}$ \\
\hline Observations & 1,009 & 1,009 & 996 & 996 & 1,009 & 1,009 \\
\hline
\end{tabular}




\section{Discussion}

Our findings illustrate that informal social safety nets were collectively used more than formal government or non-profit support systems, with over half of rural Westerners engaging in at least one form of social support. While giving financial assistance to friends or family was the most widespread form of informal support, doubling up was likewise widely used by rural Westerners during the summer of 2020. Nearly a fifth of the population had a friend or family member move into their household since the pandemic began. Even as an undercount, our estimate of $19.3 \%$, CI $[15.9 \%, 22.7 \%]$ of the population doubling up is already higher than recorded national-level peaks following the 2008 financial recession (Mykyta and Macartney 2012). This suggests several possibilities that need further investigation: doubling up may be more widely practiced in rural regions generally, doubling up may be increasingly prevalent during pandemic conditions, or possibly some interaction of the two.

Specific demographic groups also relied more extensively on doubling up than others, notably respondents who identify as mixed race or women. The significance of the presence of children in the household as a mediating variable for the effects of sex on doubling up, suggests an important possible distinction for Covid-era household sharing. While existing literature on the subject emphasizes doubling up as a response to financial hardship, our results suggest that some of the doubling up observed in our study may be in response to the sudden closure of childcare services and schools (Malik et al. 2020). In this possible scenario, it was not necessarily the individuals moving into a new household who were experiencing financial hardship, but rather those receiving new household members who were in need for childcare support. Further research should examine whether the pandemic has created a unique, childcare-based need for shared households, and the extent to which doubling up is being practiced during the ongoing lack of childcare services and school closures.

Informal social support was followed by government programs as the second most widely used safety net. While rural West utilization of some programs (e.g. Social Security and Unemployment Insurance) was on par with national-level use, our results suggest that there are specific government programs which were used at far lower rates among rural West residents, namely Medicaid, SNAP, and the CARES Act stimulus payment. This may in part be the result of varying levels of pandemic impacts across geographies, reflecting that, during the summer of 2020 , rural areas were less hard hit by the pandemic than urban regions. It may also be the case that program use was underreported due to stigmas around receiving government assistance. However, given the documented spike in unemployment in this region (blinded self-citation) and self-reported negative pandemic impacts, these lower rates of program use suggest obstacles in access to formal government programs among rural residents.

Most notably, receipt of CARES Act stimulus payments was nearly $14 \%$ lower among rural West residents than for the national population during approximately the same time period. It is not clear whether these payments were more delayed within our rural sample frame than nationally, or whether they were simply never delivered. By the time our survey was fielded, all CARES stimulus payments had been distributed to eligible taxpayers for whom the IRS had direct deposit or mailing information, suggesting that this gap likely resulted from differences in eligibility and/or limits to accessibility for "non-filers", who had to actively submit information to the IRS online to receive a payment. Given that non-filers tend to be less-educated, earn less income, and older (Cilke 1998), it is possible that there tend to be more non-filers in rural regions, contributing to this rural stimulus gap. Further, limited access to the internet and closure of information access points such as libraries may have posed additional barriers for those who had to proactively submit information to the IRS to receive a payment.

Of the three broad types of safety nets examined, non-profit support was utilized the least among rural residents. This is not entirely surprising given the documented scarcity of such organizations in rural areas. However, it is notable that use of food bank resources was high in the rural West compared to pre-pandemic national food bank utilization estimates - surprising given that food banks have historically struggled to meet the needs of geographically dispersed rural populations (Feeding America n.d.; Swenson 2020). This suggests that national-level projections of rising food insecurity during the pandemic (Gundersen et al. 2020) were starting to be reflected in rural communities. 
Our findings indicate that use of all three forms of safety net use - government, non-profit-based, and informal social support - varied significantly across all demographic groups examined. However, the same demographic characteristics do not consistently predict different types of safety net use. For example, while older residents were more likely to participate in government safety net programs, they were less likely to receive financial assistance from friends or family compared to younger people. These findings suggest the possibility of both different levels of pandemic impacts and uneven access to or knowledge of safety net resources, mirroring findings from non-rural pandemic research and environmental disaster literature. This further points to the ongoing need for research that examines the experiences and needs of specific demographic groups in rural areas (Probst et al. 2004), and does not treat rural populations as monolithic.

Finally, we find that those most negatively impacted by the pandemic were also the most actively participating in both government programs and informal social support, suggesting that both safety nets play an important role in pandemic relief. Rural Westerners who reported negative impacts on their household finances also reported significantly higher levels of giving financial assistance to friends or family. While we cannot fully disentangle whether reported financial hardship was the result of this giving, completely independent, or some combination of the two, this does suggest that many of those most burdened by the pandemic were financially supporting people beyond their immediate households. This phenomenon, a sort of secondary financial burden, is in keeping with literature that has described the importance of social networks in facilitating disaster recovery for specific demographic groups, especially low income earners (Hawkins and Maurer 2010).

\section{Conclusions}

Across the rural West, informal social support systems were the most widely used safety net during the pandemic summer of 2020. From one vantage point, these trends seem to confirm common narratives of the "self-reliant nature of rural places," which draw on strong community bonds to overcome hardship (Cutter et al. 2016:1238). Certainly, our results suggest widespread reliance on friends or family in response to several pandemic impacts, including financial hardship and lack of childcare. However, an overly rosy interpretation of these trends as simply rural "resilience" overlooks a number of critical issues.

First, resilience scholar Daniel Aldrich warns that post-disaster social capital can be a "double-edged sword" which provides benefits to only a subset of residents, excluding out-groups or the more marginalized. In essence, informal social support is not a public good, and is therefore not equally available, as public goods in theory are (Aldrich 2012; Aldrich and Crook 2008). Second, narrow depictions of rural resilience can further obscure the ways that pre-disaster socio-economic conditions created unevenly distributed vulnerabilities to disaster impacts (Cretney 2018). Additionally, an overemphasis on the benefits of informal, community-based responses to a disaster can de-emphasize the culpability and obligations of governments. Our findings suggest that a number of key government programs which were designed to support households in financial distress in fact were not utilized in rural regions to the same extent that they were nationally. More research is needed to understand why these rural government service gaps exist, and what can be done to address the obstacles of service provision posed by geographically distributed populations and limits to internet access. Finally, helping behaviors such as sending money to a family member or letting a friend move into one's home, while expressions of strong social ties, can also themselves be burdensome. Paying for a family member's rent because they lost their job and were unable to access government resources might be better termed survival than resilience.

Following the 2008 recession - the closest analogue to the Covid-19 pandemic in recent history - rural regions in the United States experienced accelerated population loss, lagged employment recovery (United States Department of Agriculture 2017), and higher rates of uninsurance compared to metropolitan counties (Bennett et al. 2018). If recovery from the pandemic is anything like recovery from the financial crisis, rural communities will clearly need robust, regionally-tailored support. Our survey results show the importance of informal support during times of crisis when other programs are less flexible and poverty rates are rising. As the pandemic stretches into a second year, the ability of informal social support to continue mitigating its impacts in rural communities will be tested. This study offers a first assessment of safety net use in the rural U.S., which is a critical first step in developing effective disaster response and recovery strategies. 


\section{Acknowledgements}

We thank Katie Pofahl for her research support and feedback on the manuscript. This work was supported by the National Science Foundation [grant number 2029990]. Any opinions, findings, and conclusions or recommendations expressed in this material are those of the authors and do not necessarily reflect the views of the National Science Foundation.

\section{References}

Aldrich, Daniel P. 2012. Building Resilience Social Capital in Post-Disaster Recovery. Chicago: The University of Chicago Press.

Aldrich, Daniel P., and Kevin Crook. 2008. "Strong Civil Society as a Double-Edged Sword: Siting Trailers in Post-Katrina New Orleans." Political Research Quarterly 61(3):379-89. doi: 10.1177/1065912907312983.

Amaro, Gabriel, and Kate Willyard. 2020. "How Resilient Are Communities to Disasters?" The United States Census Bureau. Retrieved July 14, 2020 (https://www.census.gov/library/stories/2020/06/how-resilient-arecommunities-to-disasters.html).

Ameh, Governor G., Anuli Njoku, Jeff Inungu, and Mustafa Younis. 2020. "Rural America and Coronavirus Epidemic: Challenges and Solutions." European Journal of Environment and Public Health 4(2):em0040. doi: $10.29333 /$ ejeph $/ 8200$.

American Association for Public Opinion Research. 2016. "Standard Definitions: Final Dispositions of Case Codes and Outcomes Rates for Surveys." 81.

Arcaya, Mariana C., Yael Nidam, Andrew Binet, Reann Gibson, and Vedette Gavin. 2020. "Rising Home Values and Covid-19 Case Rates in Massachusetts." Social Science \& Medicine 113290. doi: 10.1016/j.socscimed.2020.113290.

Bennett, Kevin J., Matthew Yuen, and Francisco Blanco-Silva. 2018. "Geographic Differences in Recovery after the Great Recession." Journal of Rural Studies 59:111-17. doi: 10.1016/j.jrurstud.2018.02.008.

Bitler, Marianne, and Hilary Hoynes. 2015. "Heterogeneity in the Impact of Economic Cycles and the Great Recession: Effects within and across the Income Distribution." American Economic Review 105(5):154-60. doi: $10.1257 /$ aer.p20151055.

Bitler, Marianne, Hilary Hoynes, and Diane Whitmore Schanzenbach. 2020a. The Social Safety Net in the Wake of COVID-19. w27796. Cambridge, MA: National Bureau of Economic Research.

Bitler, Marianne, Hilary Hoynes, and Diane Whitmore Schanzenbach. 2020b. "Why the Safety Net Might Not Respond as Effectively to COVID-19 As It Should." Milbank Memorial Fund. Retrieved November 6, 2020 (https://www.milbank.org/quarterly/opinions/why-the-safety-net-might-not-respond-as-effectively-tocovid-19-as-it-should/).

Blum, Dani. 2020. "For Grandparents, Filling In for Child Care Can Be 'Wonderful and Exhausting." The New York Times, May 12.

Center for Medicare \& Medicaid Services. 2020. Medicaid and CHIP Enrollment Trends through July 2020.

Cheng, Kent Jason G., Yue Sun, and Shannon M. Monnat. 2020. "COVID-19 Death Rates Are Higher in Rural Counties With Larger Shares of Blacks and Hispanics." The Journal of Rural Health 36(4):602-8. doi: https://doi.org/10.1111/jrh.12511.

Cilke, Jim. 1998. A Profile of Non-Filers. Office of Tax Analysis. Washington, D.C.: U.S. Department of the Treasury.

Clark, Eva, Karla Fredricks, Laila Woc-Colburn, Maria Elena Bottazzi, and Jill Weatherhead. 2020. "Disproportionate Impact of the COVID-19 Pandemic on Immigrant Communities in the United States." PLOS Neglected Tropical Diseases 14(7):e0008484. doi: 10.1371/journal.pntd.0008484. 
Cohn, D'vera. 2020. "About a Fifth of U.S. Adults Moved Due to COVID-19 or Know Someone Who Did." Pew Research Center. Retrieved December 17, 2020 (https://www.pewresearch.org/fact-tank/2020/07/06/abouta-fifth-of-u-s-adults-moved-due-to-covid-19-or-know-someone-who-did/).

Coibion, Olivier, Yuriy Gorodnichenko, and Michael Weber. 2020. How Did U.S. Consumers Use Their Stimulus Payments? NBER Working Paper Series. Cambridge, MA: National Bureau of Economic Research.

Couch, Kenneth A., Robert W. Fairlie, and Huanan Xu. 2020. "Early Evidence of the Impacts of COVID-19 on Minority Unemployment." Journal of Public Economics 192:104287. doi: 10.1016/j.jpubeco.2020.104287.

Cretney, Raven. 2018. "Rejecting and Recreating Resilience after Disaster." Pp. 80-93 in The Resilience Machine, edited by J. Bohland, S. Davoudi, and J. L. Lawrence. Routledge.

Cutter, Susan L., Kevin D. Ash, and Christopher T. Emrich. 2016. "Urban-Rural Differences in Disaster Resilience." Annals of the American Association of Geographers 106(6):1236-52. doi: 10.1080/24694452.2016.1194740.

Danziger, Sandra K. 2010. "The Decline of Cash Welfare and Implications for Social Policy and Poverty." Annual Review of Sociology 36:523-45.

Edin, Kathryn J., and H. Luke Shaefer. 2015. \$2.00 a Day: Living on Almost Nothing in America. New York: Houghton Mifflin Harcourt.

Federal Reserve Bank of St. Louis. 2020a. "Insured Unemployment Rate." FRED, Federal Reserve Bank of St. Louis. Retrieved January 17, 2021 (https://fred.stlouisfed.org/series/IURNSA).

Federal Reserve Bank of St. Louis. 2020b. "Total Households." FRED, Federal Reserve Bank of St. Louis. Retrieved January 17, 2021 (https://fred.stlouisfed.org/series/TTLHH).

Feeding America. n.d. "Millions of People in Rural Communities Struggle with Hunger." Retrieved December 18, 2020 (https://www.feedingamerica.org/hunger-in-america/rural-hunger-facts).

Frenier, Chris, Sayeh S. Nikpay, and Ezra Golberstein. 2020. "COVID-19 Has Increased Medicaid Enrollment, But Short-Term Enrollment Changes Are Unrelated To Job Losses." Health Affairs 39(10):1822-31. doi: 10.1377/hlthaff.2020.00900.

Gausman, Jewel, and Ana Langer. 2020. "Sex and Gender Disparities in the COVID-19 Pandemic." Journal of Women's Health 29(4):465-66. doi: 10.1089/jwh.2020.8472.

Gundersen, Craig, Monica Hake, Adam Dewey, and Emily Engelhard. 2020. "Food Insecurity during COVID-19." Applied Economic Perspectives and Policy. doi: 10.1002/aepp.13100.

Guo, Baorong. 2010. "Beyond the Public Safety Net: The Role of Nonprofits in Addressing Material Hardship of Low-Income Households." Nonprofit and Voluntary Sector Quarterly 39(5):784-801. doi: 10.1177/0899764009334307.

Hamidi, Shima, Sadegh Sabouri, and Reid Ewing. 2020. "Does Density Aggravate the COVID-19 Pandemic?" Journal of the American Planning Association 86(4):495-509. doi: 10.1080/01944363.2020.1777891.

Hammack, David C., and Steven Rathgeb Smith. 2018. American Philanthropic Foundations: Regional Difference and Change. Indiana University Press.

Harvey, Hope. 2020. "Cumulative Effects of Doubling Up in Childhood on Young Adult Outcomes." Demography 57(2):501-28. doi: 10.1007/s13524-020-00860-0.

Hawkins, Robert L., and Katherine Maurer. 2010. "Bonding, Bridging and Linking: How Social Capital Operated in New Orleans Following Hurricane Katrina." The British Journal of Social Work 40(6):1777-93. doi: $10.1093 / \mathrm{bjsw} / \mathrm{bcp} 087$.

Henning-Smith, Carrie E., Ashley M. Hernandez, Rachel R. Hardeman, Marizen R. Ramirez, and Katy Backes Kozhimannil. 2019. "Rural Counties With Majority Black Or Indigenous Populations Suffer The Highest Rates Of Premature Death In The US." Health Affairs 38(12):2019-26. doi: 10.1377/hlthaff.2019.00847. 
Henning-Smith, Carrie, Marizen R. Ramirez, Ashley Hernandez, Rachel Hardeman, and Katy Kozhimannil. 2019. Differences in Preventive Care Among Rural Residents by Race and Ethnicity. Minneapolis, MN: University of Minnesota Rural Health Research Center.

Henning-Smith, Carrie, Mariana Tuttle, and Katy B. Kozhimannil. 2020. "Unequal Distribution of COVID-19 Risk among Rural Residents by Race and Ethnicity." The Journal of Rural Health. doi: 10.1111/jrh.12463.

Howell, Junia, and James R. Elliott. 2018. "Damages Done: The Longitudinal Impacts of Natural Hazards on Wealth Inequality in the United States." Social Problems. doi: 10.1093/socpro/spy016.

Hsu, Tiffany. 2020. "Young Adults Take Refuge in Parents' Empty Nests." The New York Times, May 15.

Loprest, Pamela, and Demetra Nightingale. 2018. The Nature of Work and the Social Safety Net. Urban Institute.

Malik, Rasheed, Katie Hamm, Won F. Lee, Elizabeth E. Davis, and Aaron Sojourner. 2020. "The Coronavirus Will Make Child Care Deserts Worse and Exacerbate Inequality - Center for American Progress." Center for American Progress. Retrieved December 18, 2020 (https://www.americanprogress.org/issues/early-childhood/ reports/2020/06/22/486433/coronavirus-will-make-child-care-deserts- worse-exacerbate-inequality/).

Manson, Steven, Jonathan Schroeder, David Van Riper, Tracey Kugler, and Steven Ruggles. 2020. IPUMS National Historical Geographic Information System: Version 15.0 [Dataset]. Minneapolis, MN: IPUMS.

Marwell, Nicole P. 2004. "Privatizing the Welfare State: Nonprofit Community-Based Organizations as Political Actors." American Sociological Review 69(2):265-91. doi: 10.1177/000312240406900206.

Matthewman, Steve, and Kate Huppatz. 2020. "A Sociology of Covid-19." Journal of Sociology 1440783320939416. doi: 10.1177/1440783320939416.

Matthews, Kevin A., Janet B. Croft, Yong Liu, Hua Lu, Dafna Kanny, Anne G. Wheaton, Timothy J. Cunningham, Laura Kettel Khan, Ralph S. Caraballo, James B. Holt, Paul I. Eke, and Wayne H. Giles. 2017. "Health-Related Behaviors by Urban-Rural County Classification - United States, 2013." MMWR Surveillance Summaries 66(5):1-8. doi: 10.15585/mmwr.ss6605a1.

Messias, DeAnne K. Hilfinger, Clare Barrington, and Elaine Lacy. 2012. "Latino Social Network Dynamics and the Hurricane Katrina Disaster." Disasters 36(1):101-21. doi: https://doi.org/10.1111/j.1467-7717.2011. 01243.x.

Mykyta, Laryssa, and Suzanne Macartney. 2012. Sharing a Household: Household Composition and Economic Well-Being: 2007-2010. Current Population Report. United States Census Bureau.

Nelson, Lise, Laurie Trautman, and Peter B. Nelson. 2015. "Latino Immigrants and Rural Gentrification: Race, 'Illegality,' and Precarious Labor Regimes in the United States." Annals of the Association of American Geographers 105(4):841-58. doi: 10.1080/00045608.2015.1052338.

Parolin, Zachary, Megan Curran, Jordan Matsudaira, Jane Waldfogel, and Christopher Wimer. 2020. "Monthly Poverty Rates in the United States during the COVID-19 Pandemic." Poverty and Social Policy Working Paper 24.

Peters, David J. 2020. "Community Susceptibility and Resiliency to COVID-19 Across the Rural-Urban Continuum in the United States." The Journal of Rural Health 36(3):446-56. doi: https://doi.org/10.1111/ jrh.12477.

Pilkauskas, Natasha V., Irwin Garfinkel, and Sara S. McLanahan. 2014. "The Prevalence and Economic Value of Doubling Up." Demography 51(5):1667-76. doi: 10.1007/s13524-014-0327-4.

Probst, Janice C., Charity G. Moore, Saundra H. Glover, and Michael E. Samuels. 2004. "Person and Place: The Compounding Effects of Race/Ethnicity and Rurality on Health." American Journal of Public Health 94(10):1695-1703. doi: 10.2105/AJPH.94.10.1695.

Raifman, Matthew A., and Julia R. Raifman. 2020. "Disparities in the Population at Risk of Severe Illness From COVID-19 by Race/Ethnicity and Income." American Journal of Preventive Medicine 59(1):137-39. 
doi: 10.1016/j.amepre.2020.04.003.

Reid, Megan. 2013. "Disasters and Social Inequalities." Sociology Compass 7(11):984-97. doi: https: //doi.org/10.1111/soc4.12080.

Sabatello, Maya, Scott D. Landes, and Katherine E. McDonald. 2020. "People With Disabilities in COVID-19: Fixing Our Priorities." The American Journal of Bioethics 20(7):187-90. doi: 10.1080/15265161.2020.1779396.

Sadri, Arif Mohaimin, Satish V. Ukkusuri, Seungyoon Lee, Rosalee Clawson, Daniel Aldrich, Megan Sapp Nelson, Justin Seipel, and Daniel Kelly. 2018. "The Role of Social Capital, Personal Networks, and Emergency Responders in Post-Disaster Recovery and Resilience: A Study of Rural Communities in Indiana." Natural Hazards 90(3):1377-1406. doi: 10.1007/s11069-017-3103-0.

Salamon, Lester M. 1994. "The Rise of the Nonprofit Sector." Foreign Affairs 73(4):109-22. doi: $10.2307 / 20046747$.

Saloner, Brendan, Sarah E. Gollust, Colin Planalp, and Lynn A. Blewett. 2020. "Access and Enrollment in Safety Net Programs in the Wake of COVID-19: A National Cross-Sectional Survey." PLOS ONE 15(10):e0240080. doi: 10.1371/journal.pone.0240080.

Social Security Administration Research, Statistics, and Policy Analysis. 2020. "Monthly Statistical Snapshot, July 2020." Retrieved January 12, 2021 (https://www.ssa.gov/policy/docs/quickfacts/stat_snapshot/202007.html).

Stedman, Richard C., Nancy A. Connelly, Thomas A. Heberlein, Daniel J. Decker, and Shorna B. Allred. 2019. "The End of the (Research) World As We Know It? Understanding and Coping With Declining Response Rates to Mail Surveys." Society \& Natural Resources 32(10):1139-54. doi: 10.1080/08941920.2019.1587127.

Swenson, Kyle. 2020. "Can't Eat a Gift Card': Rural Food Banks Fight to Put Turkeys on the Table." Washington Post. Tach, Laura, and Kathryn Edin. 2017. "The Social Safety Net After Welfare Reform: Recent Developments and Consequences for Household Dynamics." Annual Review of Sociology 43:541-61.

Thiede, Brian C., Daniel T. Lichter, and Tim Slack. 2018. "Working, but Poor: The Good Life in Rural America?" Journal of Rural Studies 59:183-93. doi: 10.1016/j.jrurstud.2016.02.007.

Tickamyer, Ann R., and Cynthia M. Duncan. 1990. "Poverty and Opportunity Structure in Rural America." Annual Review of Sociology 16(1):67-86. doi: 10.1146/annurev.so.16.080190.000435.

United States Department of Agriculture. 2017. Rural America at a Glance, 2017 Edition.

U.S. Census Bureau. 2017. "What Is Rural America?" The United States Census Bureau. Retrieved January 4, 2021 (https://www.census.gov/library/stories/2017/08/rural-america.html).

U.S. Census Bureau. 2020a. "Household Pulse Survey: Measuring Social and Economic Impacts during the Coronavirus Pandemic." The United States Census Bureau. Retrieved January 11, 2021 (https://www.census. gov/householdpulse).

U.S. Census Bureau. 2020b. "July 1, 2020 Estimates of Population and Housing Units." The United States Census Bureau. Retrieved January 12, 2021 (https://www.census.gov/newsroom/press-releases/2020/ estimates-population-housing-units.html).

U.S. Department of Agriculture Food and Nutrition Service. 2020. "SNAP Data Tables." Retrieved January 12, 2021 (https://www.fns.usda.gov/pd/supplemental-nutrition-assistance-program-snap).

Webb, Gary R. 2018. "The Cultural Turn in Disaster Research: Understanding Resilience and Vulnerability Through the Lens of Culture." Pp. 109-21 in Handbook of Disaster Research, Handbooks of Sociology and Social Research, edited by H. Rodríguez, W. Donner, and J. E. Trainor. Cham: Springer International Publishing.

Weber, Bruce, and Kathleen Miller. 2017. "Poverty in Rural America Then and Now." Pp. 28-64 in Rural Poverty in the United States. New York, NY: Columbia University Press. 
Weber, Lauren. 2020. "States Overpaid Coronavirus Unemployment Claims, and They Want the Money Back." The Wall Street Journal, October 5.

Wiemers, Emily E. 2014. "The Effect of Unemployment on Household Composition and Doubling Up." Demography. doi: 10.1007/s13524-014-0347-0.

Wiemers, Emily E., Scott Abrahams, Marwa AlFakhri, V. Joseph Hotz, Robert F. Schoeni, and Judith A. Seltzer. 2020. Disparities in Vulnerability to Severe Complications from COVID-19 in the United States. w27294. National Bureau of Economic Research.

Wu, Viviana Chiu-Sik. 2019. "The Geography and Disparities of Community Philanthropy: A Community Assessment Model of Needs, Resources, and Ecological Environment." VOLUNTAS: International Journal of Voluntary and Nonprofit Organizations. doi: 10.1007/s11266-019-00180-x.

\section{Appendix}

\section{Full Results}


Table 5: Bivariate Linear Probability Model: Received Any Government Assistance

\begin{tabular}{|c|c|c|c|c|c|c|}
\hline & \multicolumn{6}{|c|}{ Dependent variable: } \\
\hline & \multicolumn{6}{|c|}{ Received Medicaid, Social Security, SNAP, Section 8 Vouchers, or Unemployment Insurance } \\
\hline & $(1)$ & $(2)$ & $(3)$ & $(4)$ & $(5)$ & $(6)$ \\
\hline Constant & $\begin{array}{c}0.255^{* * *} \\
(0.149,0.361)\end{array}$ & $\begin{array}{c}0.322^{* * *} \\
(0.267,0.377)\end{array}$ & $\begin{array}{c}0.372^{* * *} \\
(0.332,0.413)\end{array}$ & $\begin{array}{c}0.384^{* * *} \\
(0.341,0.428)\end{array}$ & $\begin{array}{c}0.642^{* * *} \\
(0.364,0.919)\end{array}$ & $\begin{array}{c}0.360^{* * *} \\
(0.317,0.403)\end{array}$ \\
\hline Age: $35-49$ & $\begin{array}{c}0.065 \\
(-0.067,0.198)\end{array}$ & & & & & \\
\hline Age: $50-64$ & $\begin{array}{c}0.046 \\
(-0.077,0.169)\end{array}$ & & & & & \\
\hline Age: $65+$ & $\begin{array}{c}0.357^{* * *} \\
(0.238,0.476)\end{array}$ & & & & & \\
\hline Female & & $\begin{array}{c}0.085^{* *} \\
(0.006,0.164)\end{array}$ & & & & \\
\hline Latina or Latino & & & $\begin{array}{c}-0.063 \\
(-0.203,0.077)\end{array}$ & & & \\
\hline Native American & & & & $\begin{array}{c}-0.166^{*} \\
(-0.358,0.027)\end{array}$ & & \\
\hline Mixed Race & & & & $\begin{array}{c}0.030 \\
(-0.196,0.256)\end{array}$ & & \\
\hline Other Race & & & & $\begin{array}{c}-0.187^{* * *} \\
(-0.323,-0.051)\end{array}$ & & \\
\hline High School Graduate & & & & & $\begin{array}{c}-0.313^{* *} \\
(-0.603,-0.024)\end{array}$ & \\
\hline Some College, No Degree & & & & & $\begin{array}{c}-0.241 \\
(-0.528,0.046)\end{array}$ & \\
\hline College Degree & & & & & $\begin{array}{c}-0.354^{* *} \\
(-0.637,-0.071)\end{array}$ & \\
\hline Graduate Degree & & & & & $\begin{array}{c}-0.265^{*} \\
(-0.552,0.022)\end{array}$ & \\
\hline Renter & & & & & & $\begin{array}{c}0.007 \\
(-0.093,0.106)\end{array}$ \\
\hline Observations & 974 & 988 & 966 & 945 & 997 & 1,009 \\
\hline
\end{tabular}


Table 6: Bivariate Linear Probability Model: Received Nonprofit Assistance

\begin{tabular}{|c|c|c|c|c|c|c|}
\hline & \multicolumn{6}{|c|}{ Dependent variable: } \\
\hline & \multicolumn{6}{|c|}{ Received assistance from a food pantry, community-based, or faith-based organization } \\
\hline & $(1)$ & $(2)$ & (3) & (4) & (5) & (6) \\
\hline Constant & $\begin{array}{c}0.089^{* *} \\
(0.015,0.164)\end{array}$ & $\begin{array}{c}0.057^{* * *} \\
(0.028,0.085)\end{array}$ & $\begin{array}{c}0.073^{* * *} \\
(0.048,0.097)\end{array}$ & $\begin{array}{c}0.083^{* * *} \\
(0.054,0.112)\end{array}$ & $\begin{array}{c}0.289^{* *} \\
(0.016,0.563)\end{array}$ & $\begin{array}{c}0.058^{* * *} \\
(0.036,0.080)\end{array}$ \\
\hline Age: $35-49$ & $\begin{array}{c}0.021 \\
(-0.070,0.112)\end{array}$ & & & & & \\
\hline Age: $50-64$ & $\begin{array}{c}-0.040 \\
(-0.120,0.040)\end{array}$ & & & & & \\
\hline Age: $65+$ & $\begin{array}{c}-0.040 \\
(-0.118,0.039)\end{array}$ & & & & & \\
\hline Female & & $\begin{array}{c}0.036 \\
(-0.013,0.084)\end{array}$ & & & & \\
\hline Latina or Latino & & & $\begin{array}{c}0.015 \\
(-0.076,0.107)\end{array}$ & & & \\
\hline Native American & & & & $\begin{array}{c}-0.058^{* *} \\
(-0.104,-0.011)\end{array}$ & & \\
\hline Mixed Race & & & & $\begin{array}{c}-0.077^{* * *} \\
(-0.108,-0.046)\end{array}$ & & \\
\hline Other Race & & & & $\begin{array}{c}0.002 \\
(-0.086,0.091)\end{array}$ & & \\
\hline High School Graduate & & & & & $\begin{array}{c}-0.228 \\
(-0.505,0.048)\end{array}$ & \\
\hline Some College, No Degree & & & & & $\begin{array}{c}-0.211 \\
(-0.489,0.067)\end{array}$ & \\
\hline College Degree & & & & & $\begin{array}{c}-0.220 \\
(-0.497,0.056)\end{array}$ & \\
\hline Graduate Degree & & & & & $\begin{array}{c}-0.226 \\
(-0.503,0.050)\end{array}$ & \\
\hline Renter & & & & & & $\begin{array}{c}0.072^{*} \\
(-0.0002,0.144)\end{array}$ \\
\hline Observations & 974 & 988 & 966 & 945 & 997 & 1,009 \\
\hline
\end{tabular}


Table 7: Bivariate Linear Probability Model: Received Informal Social Support

\begin{tabular}{|c|c|c|c|c|c|c|}
\hline & \multicolumn{6}{|c|}{ Dependent variable: } \\
\hline & \multicolumn{6}{|c|}{ Received financial assistance from friends or family } \\
\hline & (1) & (2) & (3) & $(4)$ & (5) & (6) \\
\hline Constant & $\begin{array}{c}0.201^{* * *} \\
(0.104,0.297)\end{array}$ & $\begin{array}{c}0.096^{* * *} \\
(0.056,0.136)\end{array}$ & $\begin{array}{c}0.087^{* * *} \\
(0.059,0.116)\end{array}$ & $\begin{array}{c}0.097^{* * *} \\
(0.064,0.129)\end{array}$ & $\begin{array}{c}0.249^{*} \\
(-0.009,0.507)\end{array}$ & $\begin{array}{c}0.078^{* * *} \\
(0.049,0.108)\end{array}$ \\
\hline Age: $35-49$ & $\begin{array}{c}-0.105^{*} \\
(-0.213,0.003)\end{array}$ & & & & & \\
\hline Age: $50-64$ & $\begin{array}{c}-0.141^{* * *} \\
(-0.243,-0.038)\end{array}$ & & & & & \\
\hline Age: $65+$ & $\begin{array}{c}-0.173^{* * *} \\
(-0.271,-0.075)\end{array}$ & & & & & \\
\hline Female & & $\begin{array}{c}-0.002 \\
(-0.059,0.054)\end{array}$ & & & & \\
\hline Latina or Latino & & & $\begin{array}{c}0.049 \\
(-0.057,0.155)\end{array}$ & & & \\
\hline Native American & & & & $\begin{array}{c}0.069 \\
(-0.108,0.246)\end{array}$ & & \\
\hline Mixed Race & & & & $\begin{array}{c}0.026 \\
(-0.123,0.175)\end{array}$ & & \\
\hline Other Race & & & & $\begin{array}{c}-0.079^{* * *} \\
(-0.126,-0.032)\end{array}$ & & \\
\hline High School Graduate & & & & & $\begin{array}{c}-0.134 \\
(-0.399,0.132)\end{array}$ & \\
\hline Some College, No Degree & & & & & $\begin{array}{c}-0.158 \\
(-0.421,0.105)\end{array}$ & \\
\hline College Degree & & & & & $\begin{array}{c}-0.178 \\
(-0.438,0.083)\end{array}$ & \\
\hline Graduate Degree & & & & & $\begin{array}{c}-0.178 \\
(-0.441,0.085)\end{array}$ & \\
\hline Renter & & & & & & $\begin{array}{c}0.099^{* *} \\
(0.006,0.192)\end{array}$ \\
\hline Observations & 974 & 988 & 966 & 945 & 997 & 942 \\
\hline
\end{tabular}


Table 8: Bivariate Linear Probability Model: Gave Informal Social Support

\begin{tabular}{|c|c|c|c|c|c|c|}
\hline & \multicolumn{6}{|c|}{ Dependent variable: } \\
\hline & \multicolumn{6}{|c|}{ Gave financial assistance to friends or family } \\
\hline & $(1)$ & $(2)$ & (3) & $(4)$ & $(5)$ & (6) \\
\hline Constant & $\begin{array}{c}0.393^{* * *} \\
(0.268,0.518)\end{array}$ & $\begin{array}{c}0.364^{* * *} \\
(0.306,0.423)\end{array}$ & $\begin{array}{c}0.356^{* * *} \\
(0.315,0.397)\end{array}$ & $\begin{array}{c}0.360^{* * *} \\
(0.315,0.404)\end{array}$ & $\begin{array}{c}0.408^{* * *} \\
(0.120,0.697)\end{array}$ & $\begin{array}{c}0.378^{* * *} \\
(0.333,0.422)\end{array}$ \\
\hline Age: $35-49$ & $\begin{array}{c}0.031 \\
(-0.119,0.180)\end{array}$ & & & & & \\
\hline Age: $50-64$ & $\begin{array}{c}0.013 \\
(-0.128,0.154)\end{array}$ & & & & & \\
\hline Age: $65+$ & $\begin{array}{c}-0.101 \\
(-0.236,0.033)\end{array}$ & & & & & \\
\hline Female & & $\begin{array}{c}0.031 \\
(-0.052,0.114)\end{array}$ & & & & \\
\hline Latina or Latino & & & $\begin{array}{c}0.176^{* *} \\
(0.022,0.329)\end{array}$ & & & \\
\hline Native American & & & & $\begin{array}{c}0.166 \\
(-0.096,0.428)\end{array}$ & & \\
\hline Mixed Race & & & & $\begin{array}{c}0.101 \\
(-0.128,0.331)\end{array}$ & & \\
\hline Other Race & & & & $\begin{array}{c}0.179^{*} \\
(-0.008,0.365)\end{array}$ & & \\
\hline High School Graduate & & & & & $\begin{array}{c}-0.099 \\
(-0.402,0.204)\end{array}$ & \\
\hline Some College, No Degree & & & & & $\begin{array}{c}-0.009 \\
(-0.307,0.289)\end{array}$ & \\
\hline College Degree & & & & & $\begin{array}{c}-0.002 \\
(-0.298,0.293)\end{array}$ & \\
\hline Graduate Degree & & & & & $\begin{array}{c}0.036 \\
(-0.262,0.335)\end{array}$ & \\
\hline Renter & & & & & & $\begin{array}{c}0.021 \\
(-0.106,0.148)\end{array}$ \\
\hline Observations & 962 & 975 & 953 & 934 & 985 & 933 \\
\hline
\end{tabular}


Table 9: Bivatiate Linear Probability Model: Doubling Up

\begin{tabular}{|c|c|c|c|c|c|c|c|}
\hline & \multicolumn{7}{|c|}{ Dependent variable: } \\
\hline & \multicolumn{7}{|c|}{ A friend or family member moved into the household } \\
\hline & (1) & $(2)$ & $(3)$ & $(4)$ & $(5)$ & (6) & $(7)$ \\
\hline Constant & $\begin{array}{c}0.235^{* * *} \\
(0.129,0.341)\end{array}$ & $\begin{array}{c}0.153^{* * *} \\
(0.108,0.198)\end{array}$ & $\begin{array}{c}0.174^{* * *} \\
(0.141,0.206)\end{array}$ & $\begin{array}{c}0.182^{* * *} \\
(0.145,0.218)\end{array}$ & $\begin{array}{c}0.233^{*} \\
(-0.005,0.471)\end{array}$ & $\begin{array}{c}0.187^{* * *} \\
(0.150,0.224)\end{array}$ & $\begin{array}{c}0.171^{* * *} \\
(0.134,0.207)\end{array}$ \\
\hline Age: $35-49$ & $\begin{array}{c}-0.035 \\
(-0.159,0.090)\end{array}$ & & & & & & \\
\hline Age: $50-64$ & $\begin{array}{c}-0.042 \\
(-0.160,0.076)\end{array}$ & & & & & & \\
\hline Age: $65+$ & $\begin{array}{c}-0.093 \\
(-0.206,0.019)\end{array}$ & & & & & & \\
\hline Female & & $\begin{array}{c}0.083^{* *} \\
(0.015,0.152)\end{array}$ & & & & & \\
\hline Latina or Latino & & & $\begin{array}{c}0.140^{*} \\
(-0.003,0.282)\end{array}$ & & & & \\
\hline Native American & & & & $\begin{array}{c}-0.005 \\
(-0.178,0.168)\end{array}$ & & & \\
\hline Mixed Race & & & & $\begin{array}{c}0.243^{* *} \\
(0.013,0.472)\end{array}$ & & & \\
\hline Other Race & & & & $\begin{array}{c}0.038 \\
(-0.110,0.185)\end{array}$ & & & \\
\hline High School Graduate & & & & & $\begin{array}{c}-0.068 \\
(-0.316,0.181)\end{array}$ & & \\
\hline Some College, No Degree & & & & & $\begin{array}{c}-0.010 \\
(-0.257,0.237)\end{array}$ & & \\
\hline College Degree & & & & & $\begin{array}{c}-0.076 \\
(-0.319,0.167)\end{array}$ & & \\
\hline Graduate Degree & & & & & $\begin{array}{c}-0.026 \\
(-0.273,0.221)\end{array}$ & & \\
\hline Renter & & & & & & $\begin{array}{c}0.050 \\
(-0.062,0.161)\end{array}$ & \\
\hline Child in Household & & & & & & & $\begin{array}{c}0.083^{* *} \\
(0.001,0.165) \\
\end{array}$ \\
\hline Observations & 974 & 988 & 966 & 945 & 997 & 942 & 973 \\
\hline
\end{tabular}

Use of only complete cases causes total observations to vary across models. 


\section{Calculation Methods for National-Level Statistics}

2.1. Medicaid: We calculated the national rate of Medicaid use by dividing the Center for Medicare \& Medicaid Service's July 2020 estimate of total individuals enrolled in Medicaid by the total U.S. population estimate for July 1, $2020(329,484,123)$ (Center for Medicare \& Medicaid Services 2020; U.S. Census Bureau 2020b).

2.2. Social Security: The reported national rate of Social Security use was based on the number of individuals receiving Social Security payments $(61,585,000)$ according to the Social Security Administration's July 2020 estimate (Social Security Administration Research, Statistics, and Policy Analysis 2020). We divided this statistic by the total U.S. population estimate for July 1, 2020 (U.S. Census Bureau 2020b).

2.3. SNAP: We calculated national estimates of household SNAP use by dividing the U.S. Department of Agriculture's most recently available count of total enrolled households (U.S. Department of Agriculture Food and Nutrition Service 2020) divided by the Federal Reserve Bank of St. Louis' estimate of total households in the U.S. during the year of 2020 (Federal Reserve Bank of St. Louis 2020b).

2.4. CARES Act Stimulus: The statistic from Coibion et. al. 2020 is based on a nationally representative survey of individual respondents from July 2020, whereas our survey responses were collected at the household level. To evaluate whether the observed gap in stimulus receipt may be the result of this difference, we compare our findings with an additional measure of stimulus receipt. According to the U.S. Census Bureau Household Pulse survey, $84.5 \%$ of the national population has received or expects to soon receive stimulus assistance for approximately the same time period based on household responses (U.S. Census Bureau 2020a). This finding generally concurs with Coibion et. al. 2020, suggesting that there was indeed a gap between rural-specific and national-level CARES Act stimulus receipt. We calculated the point estimate of national stimulus receipt with the Phase 1 Household Pulse Survey data, which was collected and disseminated on a weekly basis from April 23, 2020-July 16, 2020. We specifically used the last one-week period, Week 12, of Phase 1, which coincided with the final week of our survey during July 2020. Week 12 Household Pulse Survey results were taken during July 16-21, 2020. We calculated the total number of respondents who reported that "someone in household already received, or plans to receive, a stimulus payment" divided by the total number of respondents.

\section{Survey Instrument Questions}

I am going to read you a list of aspects of life that have been impacted by the coronavirus pandemic. Using a 10-point scale, I'd like you to tell me how it has impacted that aspect of your life personally. On this scale, 1 is "extremely negative," 10 is "extremely positive," and 5 is no impact at all. Here is the first one ... (RANDOMIZE).

- Your life, overall

- Your household finances

- Your mental health

- Your physical health

Next, here is a list of types of assistance. For each one I read, I'd like you to tell me whether you or anyone in your household received that type of assistance in 2019 before the coronavirus pandemic, whether they have received it in the past month, both, or neither. (RANDOMIZE)

- Financial support from family or friends

- Supplies from a food bank

- Financial support from community-based organizations or faith-based organizations

- Unemployment benefits

- Medicaid 
- Social Security benefits

- SNAP or food stamps

- Section 8 Housing Choice Voucher

- Coronavirus stimulus check

Since the pandemic began, have other people moved in with you, like friends or family members? If so, how many? (RECORD VERBATIM NUMERIC RESPONSE)

Before the COVID pandemic, did you live in a place that you considered to be permanent and stable housing, that is, you could stay there for a year or more?

- Yes

- No

- (DON'T READ) DK/NA

Do you consider where you live now to be permanent and stable housing, that is, you could stay there for a year or more?

- Yes

- No

- (DON'T READ) DK/NA

In 2019, before the pandemic, had you given any financial support to family or friends, for example, providing someone else with money for rent payments or to buy groceries?

- Yes

- No

- (DON'T READ) DK/NA

Since the pandemic began, have you given any financial support to family or friends?

- Yes

- No

- (DON'T READ) DK/NA

During 2019 before the COVID-19 pandemic, did you have medical or health insurance?

- Yes

- No

- (DON'T READ) DK/NA

During the past month, did you have medical or health insurance?

- Yes

- No

- (DON'T READ) DK/NA 